\title{
Basigin Binds Spike S on SARS-CoV2
}

\author{
Patrick William Chambers \\ Department of Pathology, Torrance Memorial Medical Center, Torrance, USA \\ Email:pwc@gte.net
}

How to cite this paper: Chambers, P.W. (2021) Basigin Binds Spike S on SARS-CoV2. Open Access Library Journal, 8: e8064. https://doi.org/10.4236/oalib.1108064

Received: October 11, 2021

Accepted: November 13, 2021

Published: November 16, 2021

Copyright $\odot 2021$ by author(s) and Open Access Library Inc.

This work is licensed under the Creative Commons Attribution International License (CC BY 4.0).

http://creativecommons.org/licenses/by/4.0/

\begin{abstract}
The Spike S/Basigin (BSG) interaction, validated in 2020, has since been called putative, postulated, and controversial. Two widely referenced articles have been largely responsible for this. The data presented here demonstrate that the exclusion of this interaction that these articles purport to show is due to an inappropriate binding affinity reference value. Spike S/BSG binding avidity is admittedly weaker than that of RH5 (falciparum epitope)/BSG by oligomeric methods, but one cannot then exclude its existence by using a monomeric binding affinity value. Additional clinical and laboratory support for this Spike S/BSG interaction is presented, including the obesity paradox and thrombotic microangiopathy (TMA). Furthermore, BSG is up-regulated in those with comorbidities, something not considered in these two articles.
\end{abstract}

\section{Subject Areas}

Pathology

\section{Keywords}

Oligomeric, RH5, Epitope, Glycan, Kd, CD147

\section{Introduction}

There has been an abundance of articles underscoring ACE2 receptors as the entry point for SARS CoV2 (SARS2). Other possible receptors for entry have been suggested by some but deemed insignificant by others. This has significantly impeded progress for discovery on the pathogenesis of Covid-19 to the detriment of many. Basigin (BSG) also known as cluster of differentiation 147 (CD147) and extracellular mixed metalloproteinase inducer (EMMPRIN) is at the top of this "deemed insignificant" receptor list. Two articles in particular [1] [2] are most persuasive in this regard. Comparison with entry and symptoms of SARS (SARS1) is elucidating. 


\section{Discussion}

\subsection{Contrarian Articles}

In 2021 two well written peer reviewed articles appeared purporting to show no evidence of interaction between the SARS2 spike protein S and basigin or CD147 [1] [2]. These flew in the face of a Dec 2020 Chinese article reporting this as a novel route for SARS-CoV2 infection [3]. The two articles in question did not determine any binding affinities-not between RH5 (reticulocyte binding homo$\log 5$, PfRh5, P. falciparum epitope) and basigin and not between Spike S and basigin. Kd (equilibrium dissociation constant equals 1/binding affinity) values for RH5/basigin binding in general vary significantly. Monomeric binding affinity is weak (larger Kd), whereas oligomeric binding avidity is stronger (smaller Kd). These two articles convincingly demonstrated that the oligomeric binding affinity between RH5 and basigin was stronger than that between Spike $S$ and basigin, reportedly $185 \mathrm{nM}$ [3]. The monomeric Kd for Spike S/basigin has not been reported. The Oxford study employed trimers [1], whereas the Cambridge study employed tetramers [2], and the Chinese study employed dimers [3]. However, in order to support their claim of no interaction Kd's of $1.1 \mu \mathrm{M}$ [4] and $1.3 \mu \mathrm{M}$ [5] were selected respectively. These monomeric $\mathrm{Kd}$ values were determined years earlier in the same respective labs (2011 Cambridge, 2014 Oxford). A 2014 Australian study, ignored by the Oxford and Cambridge articles, reported the oligomeric binding avidity of RH5/basigin to be $43.4 \mathrm{nM}$ [6], as shown in Figure 1.

\subsection{Monomeric/Oligomeric Issue}

This monomeric/oligomeric issue is aptly demonstrated by comparing two studies. The above referenced 2014 Australian study of RH5/basigin binding used oligomers. On the other hand another 2013 Cambridge study [7] determined the $\mathrm{RH} 5 /$ basigin $\mathrm{Kd}$ to be $800 \mathrm{nM}$ (stronger affinity than the $1.0 \mu \mathrm{M} \mathrm{Kd}$ but weaker than the $43.4 \mathrm{nM} \mathrm{Kd}$ ). By using the association and dissociation rate constants and the formula for half life in that article (Figure 2) [6], one can show that the half life of RH5 was 2.8 seconds. This clearly indicates that the $800 \mathrm{nM} \mathrm{Kd}$ (and

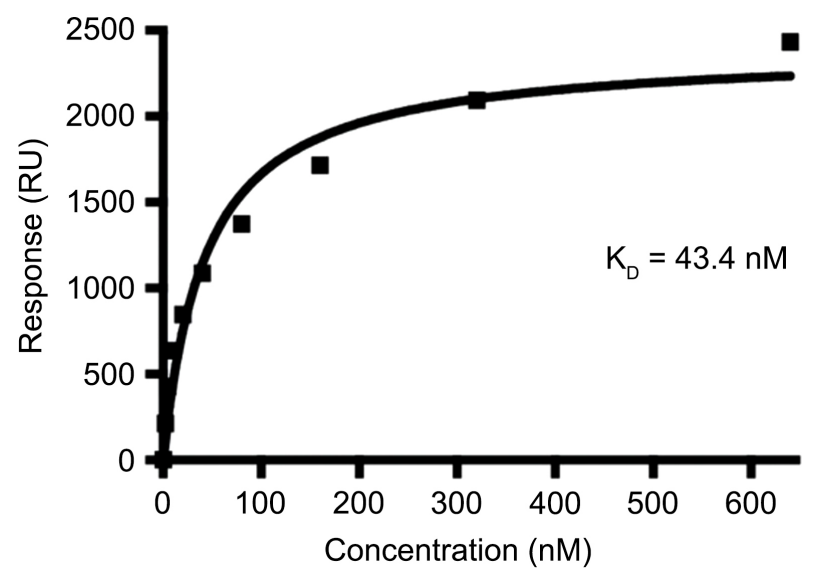

Figure 1. Oligomeric Kd for RH5/basigin [6]. 


\section{Pro- and Anti-Inflammatory Activities of Interleukin-6}

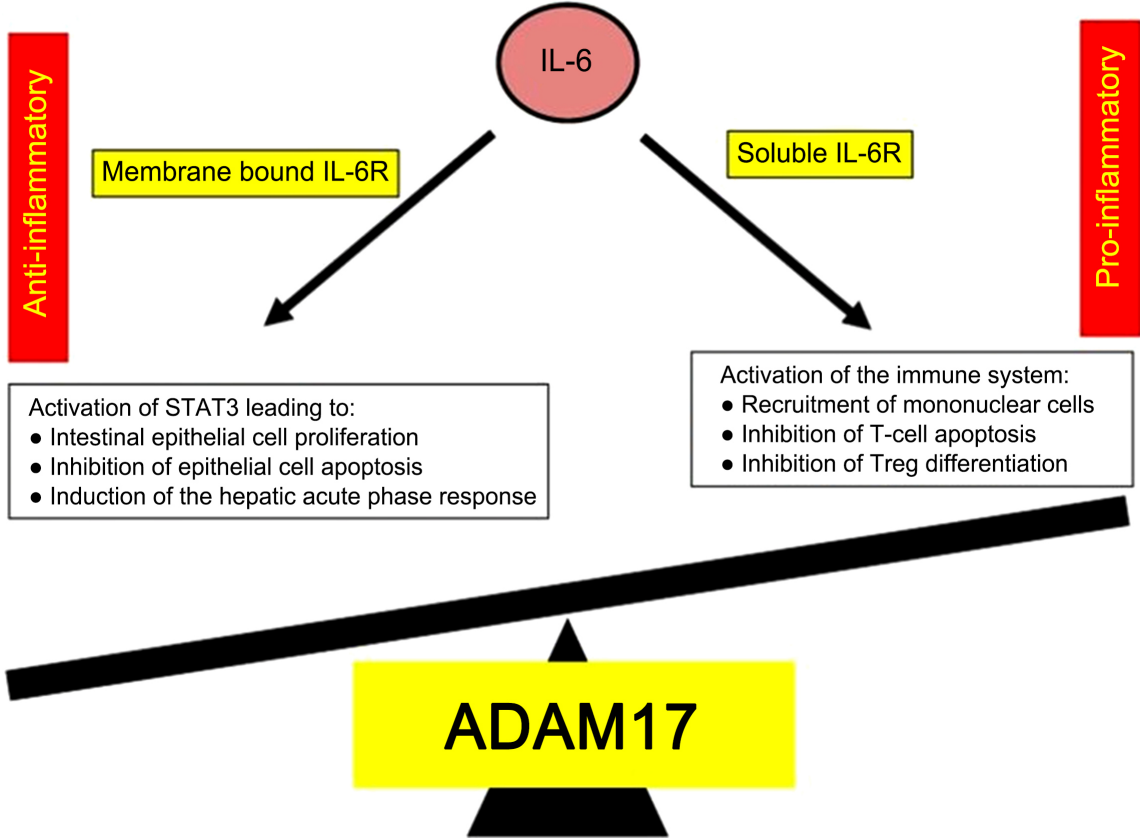

Figure 2. TACE produces TNF- $\alpha$ and upregulates IL-6. Both are adverse prognosticators) [8].

the $1.1 \mu \mathrm{M}, 1.3 \mu \mathrm{M}$ Kd's) was monomerically determined. In the exchange between the editors and authors during peer review of the Australian study on this discrepancy $(1.1 \mu \mathrm{M}, 1.3 \mu \mathrm{M} v 43.4 \mathrm{nM})$, they mutually agreed that oligomeric forms enhanced binding and produced the smaller $\mathrm{Kd}^{1}$. In October 2020 a joint Cambridge and Oxford study suggested the Kd of RH5/basigin to be $80 \mathrm{nM}$ using pentamers [9]. In that study the binding of RH5 to the BSG receptor was blocked by 10C8 monoclonal antibodies (against an epitope within RH5 domain).

\subsection{SARS1 Connection}

There is additional clinical, laboratory, and physiologic support for the interaction of CD147 with the spike protein S (SARS2) versus CD147 with the nucleocapsid protein $\mathrm{N}$ (SARS1), including comorbidity susceptibility, small vessel thrombosis, ABO preferences, organ involvement discrepancies, efficacious therapies, and erythrocyte indices (RDW or red cell distribution width) [10]. SARS1 and SARS2 both utilize the ACE2 receptors for entry. Yet obesity is protective for SARS1 [11] but a strong risk factor for SARS2 and falciparum malaria [12]. SARS1 required cyclophilin (CypA) in addition to protein $\mathrm{N}$ for CD147 receptor entry [13]. CypA, critical for entry, is up-regulated via angiotensin II and AT2Rs [14]. But obesity due to a high fat diet exhibits low AT2R activity [15], i.e., lower CypA, and is thereby protective for SARS1. How then does obesity become a risk factor for SARS2 unless its CD147 epitope doesn't utilize the ${ }^{1}$ Exchange between authors [6] and editors (Point \#2). 


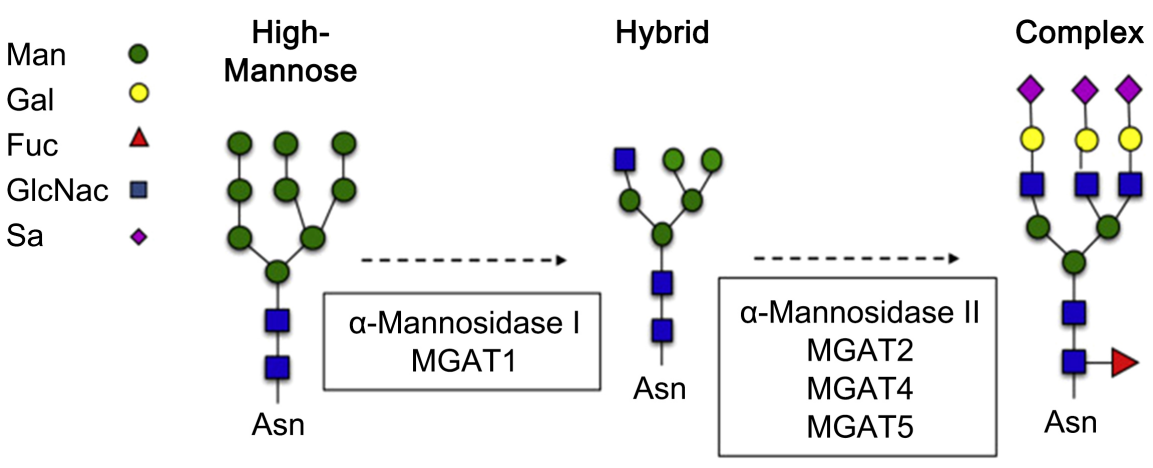

Figure 3. TNF- $\alpha$ inhibits $\alpha$-mannosidase [22], i.e., high mannose glycans are enhanced. High mannose glycans bind only to pro-inflammatory $\mathrm{CD} 6^{+}$natural killer monocytes [22].

nucleocapsid protein N/CypA but the Spike protein S for entry? Might the remarkable efficacy of meplazumab, a humanized anti-CD147 antibody, for Covid pneumonia [16] point to a significant role for CD147 in SARS2 cellular entry? Interestingly $\mathrm{P}$. falciparum provides its own exogenous source of CypA, bypassing the need for any AT2R activity [17]. These observations explain the obesity risk factor for malaria and SARS2. D-dimers are indicative of severity for SARS2 and falciparum malaria but not SARS1 [18] [19].

SARS1 and SARS2 can both culminate in ARDS. However, the obesity paradox and the prevalence of TMA seem more akin to falciparum malaria than SARS1.

\subsection{Implications}

Unfortunately this Spike S/BSG interaction has dire consequences for those with comorbidities. Destruction of ACE2 receptor bearing cells by SARS2 increases ACE/ACE2. The increased angiotensin II via AT1Rs activates ADAM17 (A Disintegrin and A Metalloproteinase 17) also known as TACE (Tumor necrosis factor Alpha Converting Enzyme) and up-regulates TNF- $\alpha$ and IL6 (interleukin 6), as shown in Figure 2, the two most prominent cytokines for the obese, the elderly and those with comorbidities [10]. IL6 upregulates CD147 receptors [20] and TNF- $\alpha$ up-regulates high mannose glycans (sugars), as shown in Figure 3, on the host CD147 receptors and S spike epitopes (of viral or vaccine origin), which are heavily glycosylated [21] [22]. Circulating lectins bind these glycans and initiate the complement and clotting cascades via mannose binding lectins (MBLs) and the lectin complement pathway (LCP) [23] [24]. This up-regulation further challenges the credibility of these two studies done on normal mammalian cells or the equivalent.

\section{Conclusion}

In summary, both articles used oligomeric methodology to demonstrate that Rh5/BSG binding exceeds that of Spike S/BSG. But they then used monomerically derived Kds (1100 nM 2011 [4], 1300 nM 2014 [5]) to validate the exclusion 
of any Spike S/BSG interaction, despite a joint 2020 Cambridge and Oxford study that yielded the $80 \mathrm{nM}$ oligomeric Kd [9]. If the proper oligomerically determined $43.4 \mathrm{nM}$ [6] or $80 \mathrm{nM} \mathrm{Kd}$ were employed, this negative threshold would have been insufficiently sensitive to detect the Spike S/BSG binding. Furthermore the obesity paradox and TMA in SARS2/malaria versus SARS1 clinically support the above interpretation. Elevated D-dimer levels provide additional laboratory support. One can only speculate on the role CD147 or BSG might play in this frequently encountered abnormal lab value (D-dimer) seen post vaccination [25], not to mention the less frequent endothelitis and clinical thrombosis in Covid 19 (SARS2), naturally acquired or otherwise. Thus it seems that the 2020 article by Wang et al. [3] should no longer be considered putative, postulated, or controversial.

\section{Conflicts of Interest}

The author declares no conflicts of interest.

\section{References}

[1] Ragotte, R.J., Pulido, D., Donnellan, F.R., Hill, M.L., Gorini, G., Davies, H., et al. (2021) Human Basigin (CD147) Does Not Directly Interact with SARS-CoV-2 Spike Glycoprotein. mSphere, 6, e00647-21. https://doi.org/10.1128/mSphere.00647-21

[2] Shilts, J., Crozier, T.W.M., Greenwood, E.J.D., Lerner, P. and Wright, G.J. (2021) No Evidence for Basigin/CD147 as a Direct SARS-CoV-2 Spike Binding or Receptor. Scientific Reports, 11, Article No. 413. https://doi.org/10.1038/s41598-020-80464-1

[3] Wang, K., Chen, W., Zhang, Z., Deng, Y., et al. (2020) CD147-Spike Protein Is a Novel Route for SARS-CoV-2 Infection to Host Cells. Signal Transduction and Targeted Therapy, 5, 283.

[4] Crosnier, C., Bustamante, L., Bartholdson, S., et al. (2011) Basigin Is a Receptor Essential for Erythrocyte Invasion by Plasmodium falciparum. Nature, 480, 534-537. https://doi.org/10.1038/nature10606

[5] Wright, K., Hjerrild, K., Bartlett, J., et al. (2014) Structure of Malaria Invasion Protein RH5 with Erythrocyte Basigin and Blocking Antibodies. Nature, 515, 427-430. https://doi.org/10.1038/nature13715

[6] Chen, L., Xu, Y., Healer, J., Thompson, J.K., Smith, B.J., Lawrence, M.C., et al. (2014) Crystal Structure of PfRh5, an Essential P. falciparum Ligand for Invasion of Human Erythrocytes. eLife, 3, e04187. https://doi.org/10.7554/eLife.04187

[7] Wanagurua, M., Liub, W., Hahn, B.H., Raynerd, J.C. and Wright, G.J. (2013) RH5Basigin Interaction Plays a Major Role in the Host Tropism of Plasmodium falciparum. PNAS, 110, 20735-20740. https://doi.org/10.1073/pnas.1320771110

[8] Rose-John, S. (2012) IL-6 Trans-Signaling via the Soluble IL-6 Receptor: Importance for the Pro-Inflammatory Activities of IL-6. International Journal of Biological Sciences, 8, 1237-1247. https://doi.org/10.7150/ijbs.4989

[9] Campeotto, I., Galaway, F., Mehmood, S., Barfod, L.K., Quinkerte, D., Kotraiah, V., et al. (2020) The Structure of the Cysteine-Rich Domain of Plasmodium falciparum P113 Identifies the Location of the RH5 Binding Site. mBio, 11, e01566-20. https://doi.org/10.1128/mBio.01566-20

[10] Chambers, P.W. (2020) COVID-19, ARDS, ACOVCS, MIS-C, KD, PMIS, TSS, MIS-A: 
Connecting the Alphabet?

[11] Ball, L., Serpa Neto, A. and Pelosi, P. (2017) Obesity and Survival in Critically Ill Patients with Acute Respiratory Distress Syndrome: A Paradox within the Paradox. Critical Care, 21, 114. https://doi.org/10.1186/s13054-017-1682-5

[12] Wyss, K., Wångdahl, A., Vesterlund, M., Hammar, U., Dashti, S., Naucler, P., et al. (2017) Obesity and Diabetes as Risk Factors for Severe Plasmodium falciparum Malaria: Results from a Swedish Nationwide Study. Clinical Infectious Diseases, 65, 949-958. https://doi.org/10.1093/cid/cix437

[13] Chen, Z., Mi, L., Xu, J., Yu, J., Wang, X., Jiang, J., et al. (2005) Function of HAb18G/CD147 in Invasion of Host Cells by Severe Acute Respiratory Syndrome Coronavirus. The Journal of Infectious Diseases, 191, 755-760.

https://doi.org/10.1086/427811

[14] Tian, H., Yu, D., Hu, Y., Zhang, P., Yang, Y., Hu, Q., et al. (2018) Angiotensin II Upregulates Cyclophilin A by Enhancing ROS Production in Rat Cardiomyocytes. Molecular Medicine Reports, 18, 4349-4355.

https://doi.org/10.3892/mmr.2018.9448

[15] Nag, S., Ali, Q., Wu, Y. and Husain, T. (2012) Angiotensin AT2R Activation Increases ACE2/Ang1-7/MasR Axis and Prevents Fatty-Diet-Induced Obesity. International Journal of Exercise Science: Conference Proceedings, 6, Article No. 6. https://digitalcommons.wku.edu/ijesab/vol6/iss2/6

[16] Bian, H., Zheng, Z.-H., Wei, D., Zhang, Z., Kang, W.-Z, Hao, C.-Q., et al. (2020) Meplazumab Treats COVID-19 Pneumonia: An Open-Labelled, Concurrent Controlled Add-On Clinical Trial. https://doi.org/10.1101/2020.03.21.20040691

[17] Berriman, M. and Fairlamb, A.H. (1998) Detailed Characterization Characterization of a Cyclophilin from the Human Malaria Parasite Plasmodium falciparum. Biochemical Journal, 334, 297-314. https://doi.org/10.1042/bj3340437

[18] Meltzer, E., Keller, S., Shmuel, S. and Schwartz, E. (2019) D-Dimer Levels in NonImmune Travelers with Malaria. Travel Medicine and Infectious Disease, 27, 104-106. https://doi.org/10.1016/j.tmaid.2018.05.004

[19] Yu, H., Qin, C., Chen, M., Wang, W. and Tian, D. (2020) D-Dimer Level Is Associated with the Severity of COVID-19. Thrombosis Research, 195, 219-225. https://doi.org/10.1016/j.thromres.2020.07.047

[20] Hu, J., Lei, L., Wang, Y., Wang, K., Hu, X., Wang, A. and Vanderkerken, K. (2016) Interleukin-6 Drives Multiple Myeloma Progression by Up-Regulating of CD147/Emmprin Expression. Blood, 128, 5632. https://doi.org/10.1182/blood.V128.22.5632.5632

[21] Scott, D.W., Chen, J., Chacko, B.K., TraylorJr, J.G., Orr, A.W. and Patel, R.P. (2012) Role of Endothelial N-Glycan Mannose Residues in Monocyte Recruitment during Atherogenesis. Thrombosis, and Vascular Biology, 32, e51-e59. https://doi.org/10.1161/ATVBAHA.112.253203

[22] Regal-McDonald, K. and Patel, R.P. (2020) Selective Recruitment of Monocyte Subsets by Endothelial NGlycans. The American Journal of Pathology, 190, 947-957. https://doi.org/10.1016/j.ajpath.2020.01.006

[23] Garred, P., Nielsen, M.A., Kurtzhals, J.A.L., Malhotra, R., Madsen, H.O., Goka, B.Q., et al. (2003) Mannose Binding Lectin Is a Disease Modifier in Clinical Malaria and May Function as Opsonin for Plasmodium falciparum-Infected Erythrocytes. Infection and Immunity, 71, 5245-5253. https://doi.org/10.1128/IAI.71.9.5245-5253.2003

[24] Knierman, M.D., Gelfanova, V., Zlatniski, N.A., Mullen, J.H., Siegel, R.W. and Konrad, R.J. (2021) Severe SARSCoV-2 Infection Treated with the Mannose Binding Lectin Associated Serine Protease 2 (MASP2) Inhibitor Narsoplimab. Journal of Al- 
lergy and Infectious Diseases, 2, 24-28. https://doi.org/10.46439/allergy.2.018

[25] Hoffa, C. (2021) D-Dimer Tests Show at Least 62 Percent of mRNA "Vaccinated" Patients Have Microscopic Blood Clots. Andara Press.

https://adarapress.com/2021/07/14/d-dimer-tests-show-at-least-62-percent-of-mrnavaccinated-patients-have-microscopic-blood-clots-reports-dr-charles-hoffe-m-d 